\title{
Just-in-Time Public Health Training and Networking in Farsi-Speaking Countries: Influenza A (H1N1) Experience
}

\author{
Ali Ardalan; ${ }^{1}$ Amir Ansari; ${ }^{2}$ Komil Daburov; ${ }^{3}$ Nasrin Rahimian; ${ }^{1}$ Mehrdad Mohajeri; ${ }^{1}$ \\ Amir Ebrahimzadeh; ${ }^{1}$ Rashid A. Chotani; ${ }^{4}$ Ronald E. LaPorte; ${ }^{5}$ Faina Linkov; ${ }^{6}$ Mita Lovalekar; ${ }^{7}$ \\ Eugene Shubnikov ${ }^{8}$
}

1. Health in Emergencies \& Disasters Department, School of Public Health and Institute of Public Health Research, Tehran University of Medical Sciences, Tehran, Iran

2. Office of the Minister, Ministry of Public Health, Afghanistan

3. School of Sanitation and Hygiene Education, Dushanbe, Tajikistan

4. Uniformed Services University of the Health Sciences, Bethesda, Maryland USA

5. Department of Epidemiology, Graduate School of Public Health (GSPH), University of Pittsburgh, Pittsburgh, Pennsylvania USA

6. School of Medicine, Univeristy of Pittsburgh, Pittsburgh, Pennsylvania USA

7. School of Health \& Rehabilitation Sciences, University of Pittsburgh, Pittsburgh, Pennsylvania USA

6. Institute of Internal Medicine, Novosibirsk, Russia

\section{Correspondence:}

\section{Ali Ardalan, MD, PhD}

Health in Emergencies and Disasters Department

National Institute of Health Research

Tehran University of Medical Sciences No 78, Italia Ave, Tehran, Iran

E-mail: aardalan@gmail.com or aardalan@tums.ac.ir

Web publication: 09 January 2010
On 27 April 2009, the World Health Organization's alert system was increased to Level 3 due to a new subtype of Influenza A, commonly referred to as "Swine Flu" (H1N1) and ultimately reached Level 6, indicating a pandemic. The new H1N1 Influenza had not been previously detected in swine or humans, and cases initially were reported in Mexico and the US, placing about 200 million people at risk.

Public health education has been known to be an effective strategy for decreasing human health risks, as well as a good global strategy to reduce the risk for disasters. Increasing use of the Internet even in developing countries, has opened a window to a rapid, low-cost method to disseminate information regarding new health risks, such as pandemics and disasters.

The Internet has been used by Supercourse to teach public health globally by disseminating about 3,700 PowerPoint files through a network of about 65,000 public health educators and professionals from 174 countries. ${ }^{1,2}$ "Justin-time" ( $I T$ ) has been utilized during disasters due to natural hazards including pandemics for education through the Supercourse lectures that were developed by a multidisciplinary group of national and international scientists/educators can rapidly disseminate the risk knowledge within days, if not hours after an the onset of an event. ${ }^{3}$ Just-in-time focuses on the golden time of public interest in a disaster. "Just-in-time" experiences have been recounted in the literature, such as its use after the tsunami in Southeast Asia, the SARS epidemic, and Hurricane Katrina. ${ }^{3-5}$ Often during times of disaster, the media and government officials may not be viewed as credible sources of information. National and international academics may be viewed as trusted sources, but rarely are sought out during times of crisis. In this letter, we recount the experience of creating a Farsi language JIT lecture on H1N1, and the lessons learned from working with a multinational team.

On 26 April 2009, the day after the first case of H1N1 was diagnosed, a JIT lecture regarding the H1N1 outbreak was built through Supercourse and was subsequently updated regularly. 1,5 The lecture was uploaded in HTML format and free access to the PowerPoint file was permitted. Fifteen versions of the lecture have been uploaded so far. To minimize the time between lecture development and classroom presentation, the lecture was translated into different languages, including Spanish, Chinese, and Arabic. A team comprised of medical students from the Tehran University of Medical Sciences joined the JT team on 28 April and translated the H1N1 lecture into Farsi, which is the official language of about 106 million people residing in three countries: Iran, Afghanistan, and Tajikistan.

Table 1 provides Internet penetration rate in the these countries, and the related growth rate from 2000 to 2008 . Although Internet penetration in these countries is considerably less than some other Asian countries, their user growth rates are among the highest during this period. According to World Internet Stats, Afghanistan and Tajikistan's growth rates ranked first and third in Asia, respectively. This can be attributed to globalization and the political stability and economic development in these areas in recent years. 


\begin{tabular}{|c|c|c|c|}
\hline Country & Population & Users & $\begin{array}{c}\text { Penetration } \\
\text { rate (\%) }\end{array}$ \\
\hline Iran \\
\hline 2000 & $69,442,905$ & 250,000 & 3.80 \\
\hline 2005 & $69,442,905$ & $7,500,000$ & 10.80 \\
\hline 2008 & $65,875,223$ & $23,000,000$ & 34.90 \\
\hline Afghanistan \\
\hline 2000 & $21,770,000$ & 1,000 & 0.005 \\
\hline 2005 & $27,089,593$ & 300,000 & 1.10 \\
\hline 2008 & $32,738,376$ & 500,000 & 1.50 \\
\hline Tajikistan & \multicolumn{3}{|c|}{} \\
\hline 2000 & $6,702,382$ & 2,000 & 0.10 \\
\hline 2005 & $6,702,382$ & 19,500 & 0.30 \\
\hline 2008 & $7,211,884$ & 484,200 & 6.70 \\
\hline \multicolumn{4}{|c|}{ Ardalan 62009 Prehospital and Disaster Medicine }
\end{tabular}

Table 1-Populations, Internet users, and penetration rates in Farsi-speaking countries

Source: World Internet Stats

Traffic on the Farsi site was not heavy, but among the visitors included the head of the Iranian CDC's Influenza Program and an advisor to Minister of Public Health in Afghanistan, who used some parts of the lecture for media interviews and to increase public awareness. Moreover, the PowerPoint version typically is used to present to students in a classroom; thus there is a multiplicative effect.

The low visitor rate to the Influenza Farsi-lecture can be explained in a few ways. There was a very little public attention and not much of a sense of emergency, as no cases of

H1N1 were officially reported. Additionally, the Supercourse concept and network is new to the targeted Farsi-speaking communities. The Internet penetration rate is low in these communities, despite its rapid growth rate. Also, many Farsi speakers most likely chose to read the materials in their original language, so it is probable that many people in these countries visited the English version of the lecture.

Iran, Afghanistan, and Tajikistan are highly prone to disasters due to natural hazards and public health threats. This experience has helped us to plan for the next possible public health emergency in our countries. We must strengthen the network of public health professionals in the targeted countries, and use other networks to reach the maximum number of potential users. Medical/public health students have the potential to be the core of the network while receiving supervision from the senior members of the public health community. The multidisciplinary nature of threats to human health calls for a multidisciplinary source of expertise. As such, we have planned to extend our network to all related disciplines, such as engineering, seismology, climatology. If an earthquake happens in Tehran, Kabul, or Dushanbe, a call for information will be sent through the network using e-recruiting. Within a short time, ranging from hours to a couple of days, the experts from different disciplines would contribute to the lectures, translation, comments, and/or dissemination the lecture to their community and networks. ${ }^{6}$ We have applied this approach of e-recruitment in several disasters. ${ }^{3}$

So far, we have planned to maintain a Web-link between the JIT Supercourse and Ministry of Public Health (MoPH) Afghanistan and collaborate with Tajikistan public health seniors to extend the network and keep the core team ready for the next possible emergency.
References

1. Chotani RA: Translated to Farsi by Mohajeri M, Ebrahimzadeh A, Rahimian N, Ardalan A: Influenza A(H1N1) (Swine Flu): A global outbreak. Available at http://www.pitt.edu/ super1/lecture/lec34631/index.htm. Accessed on: 07 June 2009.

2. LaPorte RE: Global Health Network Supercourse. Available at http://www.pitt.edu/ super1. Accessed on: 07 June 2009.
3. Ardalan A, Linkov F, Shubnikov E, LaPorte RE: Public awareness and disaster risk reduction: Just-in-time networks and learning. Prehosp Disaster Med 2009;23:286-288.

4. Chotani RA, Laporte RE, Linkov F: Just-in-time lecture: SARS. Lancet 2003;361:1996.

5. Linkov F, Ardalan A, Dodani S, et al: Building just-in-time lectures during the prodrome of Hurricanes Katrina and Rita. Prebosp Disaster Med 2006;21(2):132.

6. LaPorte RE: E-recruiting. Nature $2004 ; 428: 876$. 